\title{
Media as a Social Need
}

\author{
Kirti Sanjay Dorchester, Apurv Chandel
}

\begin{abstract}
As the human is going through the rapid change in his social as well as in his economical aspect, it faces lot of changes in its social and ecological environment. As a result of it, social media playing a major role to connect the people from far places to communicate with each other on a platform where they can share their views. But as everything has its dark side it shows its consequences as many of people got addicted to the social media. When social media word in our mind then Facebook, WhatsApp, Instagram, LinkedIn are the most common example in it. Now a days as looking to the scenario we are able to say that media has become a social need.
\end{abstract}

Keywords: Facebook, WhatsApp, Instagram, LinkedIn, social and ecological environment.

\section{INTRODUCTION}

Increasing mobile connectivity globally has responsible for 'on the go' social activity, from catching up on friends' updates to sharing content and watching a video. As social media is having more craze in the age group of $15-32$, as looking to the traffic of interest of the users many people saw business in it and now there are referred as social sites. According to the online world internet users statistics there are 4.2 billion $[1]$ active internet user in the world i.e. more than half of the world is now using internet and imposed to the internet. Out of that 3.1 billion [2] people uses social media all across world. According to the source 5.1 billion [2] mobile user in the world. In the recent years not only the number of users increases but also there is increment in the time which people spend in social media. According to the survey average time spent by users using internet is 6 hours per day, and many of these are addicted to these. Ruder Finn, from US, measures the reasons why people go online and socializing is one of the key drivers:(3)

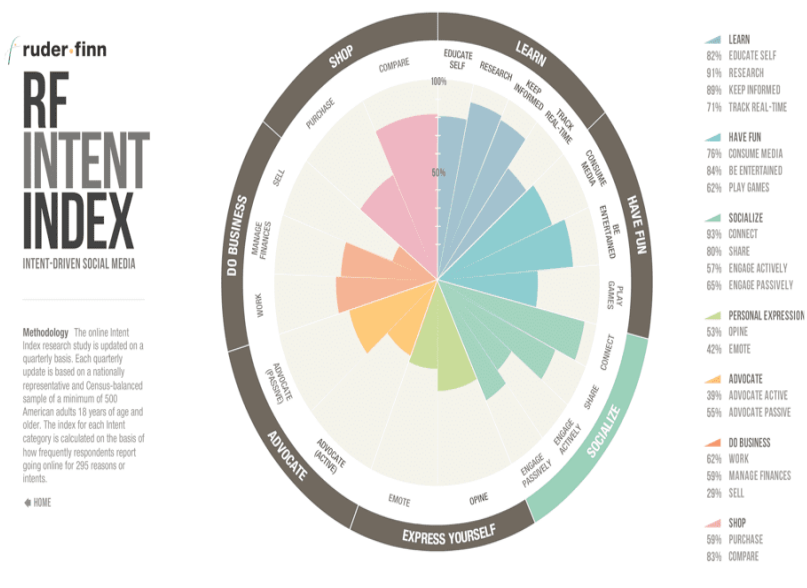

Revised Manuscript Received on September 10, 2019.

Dr. Kirti Sanjay Dorchester, Assistant Professor, Basic Sciences \& Engineering Department, Indian Institute of Information Technology, Nagpur, Maharastra, India.

Apurv Chandel, Student CSE III Sem, Indian Institute of Information Technology, Nagpur, Maharastra, India.
If we take case study of our country the facts shows that our country rank next to Saudi in the growth of social media users with annually $31 \%$ and if we will go deep in the discussion of it then the users are mostly in Facebook and the age group which is most excited is none other than the young generation of our country range of 18-34 years. Out of 6-hour Indian users spend $2 \mathrm{hr} 26 \mathrm{~min}$ in social media daily, and in social media Facebook has the crown for number of users followed by YouTube, WhatsApp, Instagram, WeChat, do and etc.

Facebook has the total 2.16 billion [2] users and YouTube with 1.5 billion then comes WhatsApp with 1.3 billion and WeChat with 980 million. These are the stats which are available on global platform but we see the effect of social in our day to day life. Now a days everyone has WhatsApp and it has been like an identity card which we use to carry and it's an obvious case that person will have a WhatsApp or Facebook account. Now a day's school and collage everywhere there is a WhatsApp group where the general information is shared.

\begin{tabular}{|l|l|l|l|}
\hline Social Media & Active User & 15-34 Ages & Indian Uses \\
\hline Facebook & 2.16 Billion & 1.58 Billion & 241 Million \\
\hline Twitter & 330 Million & 135 Million & 23.2 Million \\
\hline LinkedIn & 260 Million & 91 Million & 42 Million \\
\hline
\end{tabular}

Over this data which have been collected from the different sources shows that the people using social media is much high but that's not an issue the major problem is people waste lot of their precious time in using social media.

\section{SOCIAL MEDIA}

- Positive Points

- Negative Points

* Positive Points:

1. It is a key influencer in every social network

2. In politics awareness to the people about the value of their votes, media is also used as the platform for the government to make people aware of the various scheme of govt.

3. Interaction between the social animal increased as there is development in the communication.

4. Social movements have easy fast method of mobilizing people and sharing information.

5. Job alert is given online so people are aware about the different jobs.

6. Social media sites have created thousands of ecommerce jobs. 
7. India has become one of the IT hubs and many people have been benefited from it.

8. Purchasing decisions are influenced by social media

9. Customers are active on social media

10. Social Media provides rich customer experiences.

11. With Social media monitoring you can gain key information about your competitors.

\section{* Negative Points:}

1. Now a days many of the apps are less sensitive to user data.

2. There is always a threat to user data.

3. Sometimes there are imparities in the bank account due to online banking.

4. Due to social media post offices are in decline state slowly converting into banks.

5. Many youngsters lost their way due to the addictive games like pub and cogs.

6. People nowadays don't get exposed to real life situation rather than that they are only limit to their cell phones.

7. Now a day cyber security is a big concern for everyone.

8. Many times, using social media is waste of time and there is no productive to it.

9. Fake news is spreading everyone and there is confusion among the people what is right and what is wrong.

10. Reputations can be enhanced or destroyed on social networks

11. Negative customer reviews are harmful.

12. Highly time consuming.

\section{RELATED FACTS \& FIGURES}

\section{Demographic Composition \% of Leading Social Networks}

$=18-24=25-34=35-44=45-54=55-64=65+$

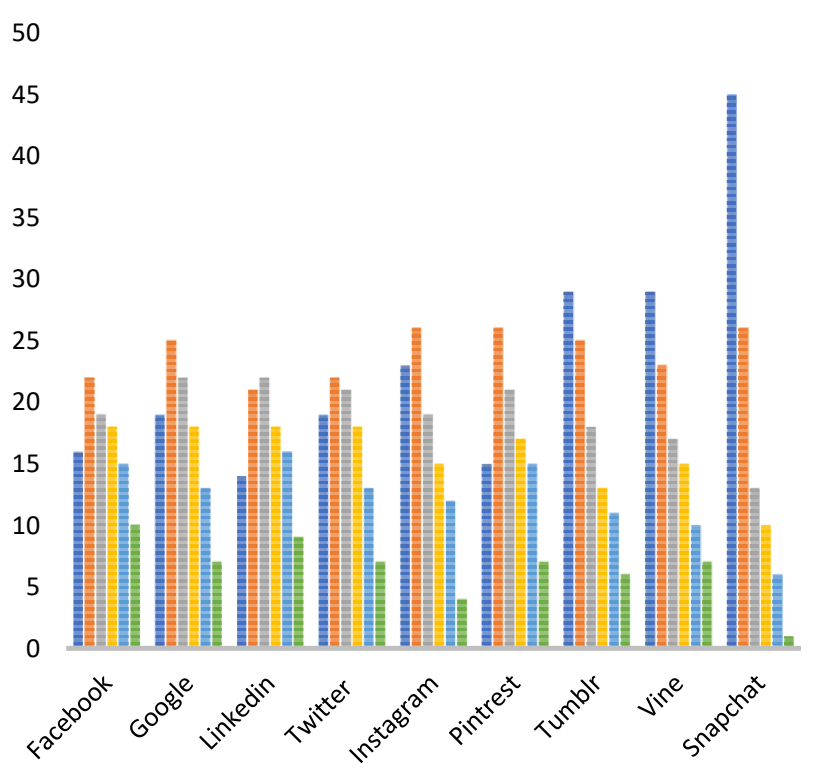

ANNUAL GROWTH OF SOCIAL MEDIA USERS
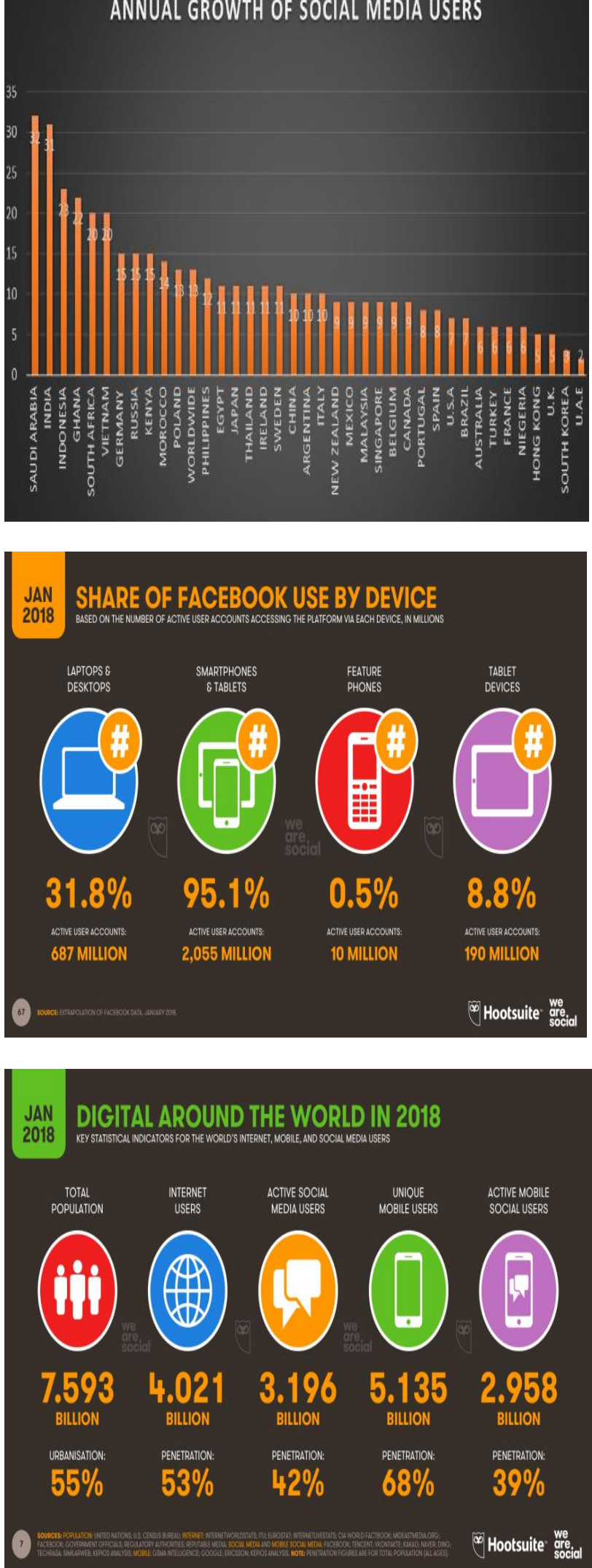

Published By:

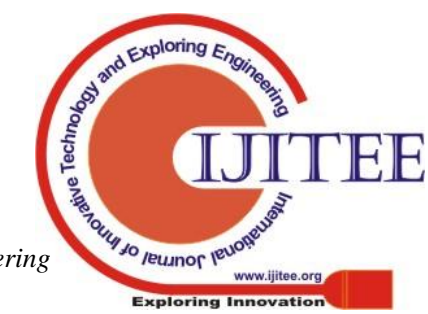




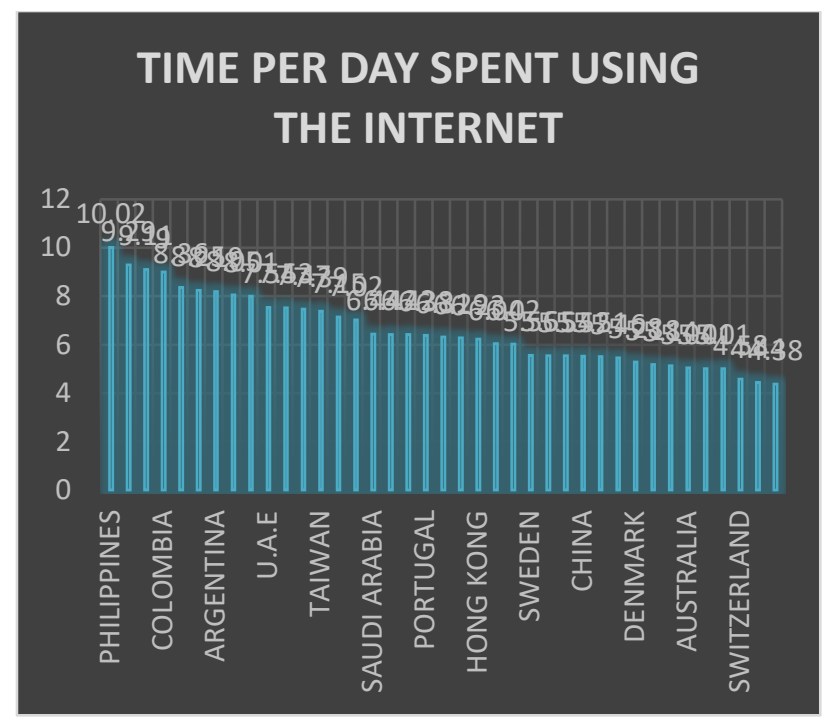

\section{SURVEY RESULTS}

We have conducted a local survey on the usage of social media in our friend circle between the age of 14-25 years. We got a positive feedback from it and we conclude from it that nowadays many of the people are using social media in larger extent and giving their lot of time to it. Survey Reference Is: https://forms.gle/vFptF44e6HVSmdf3A
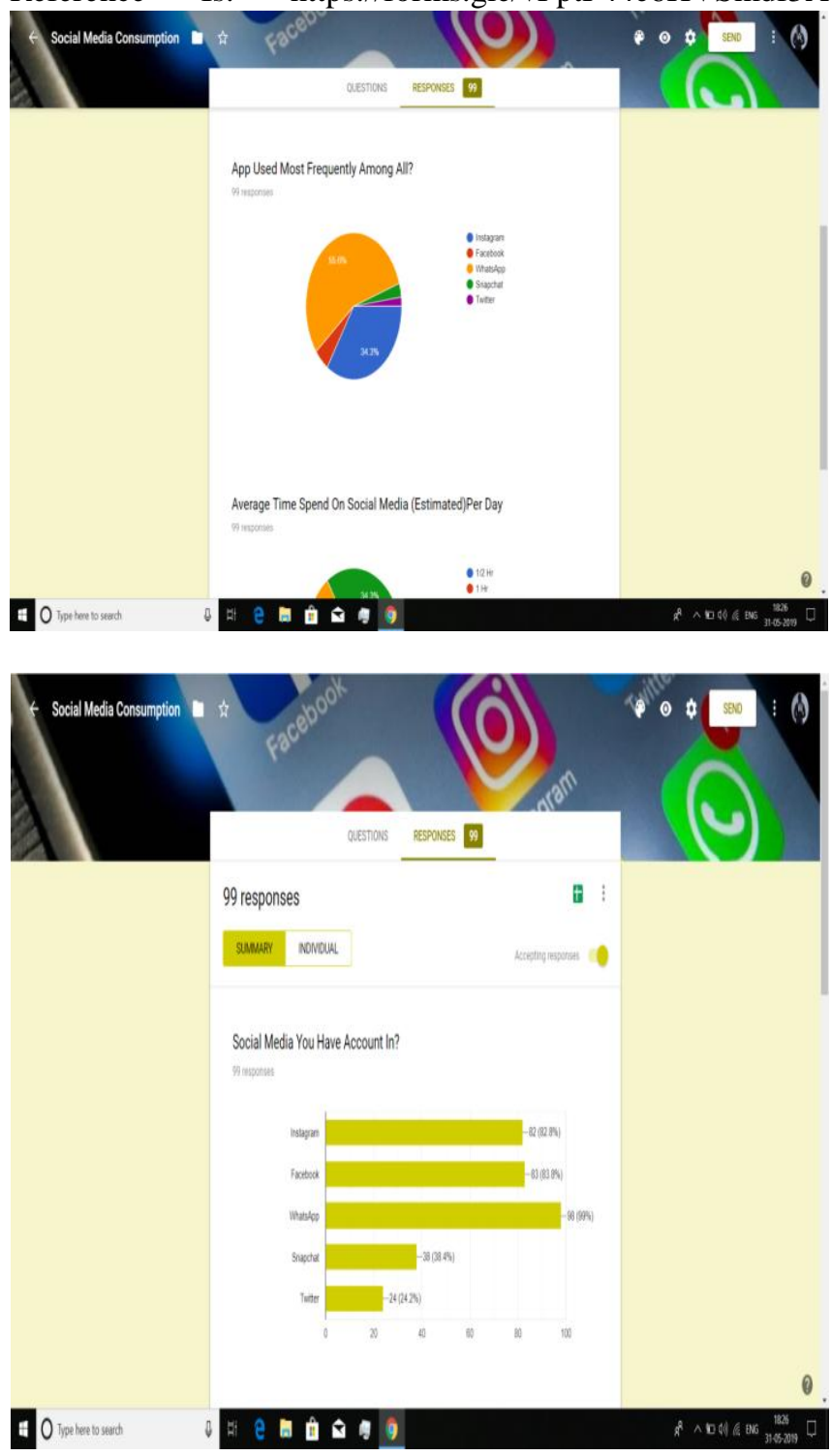

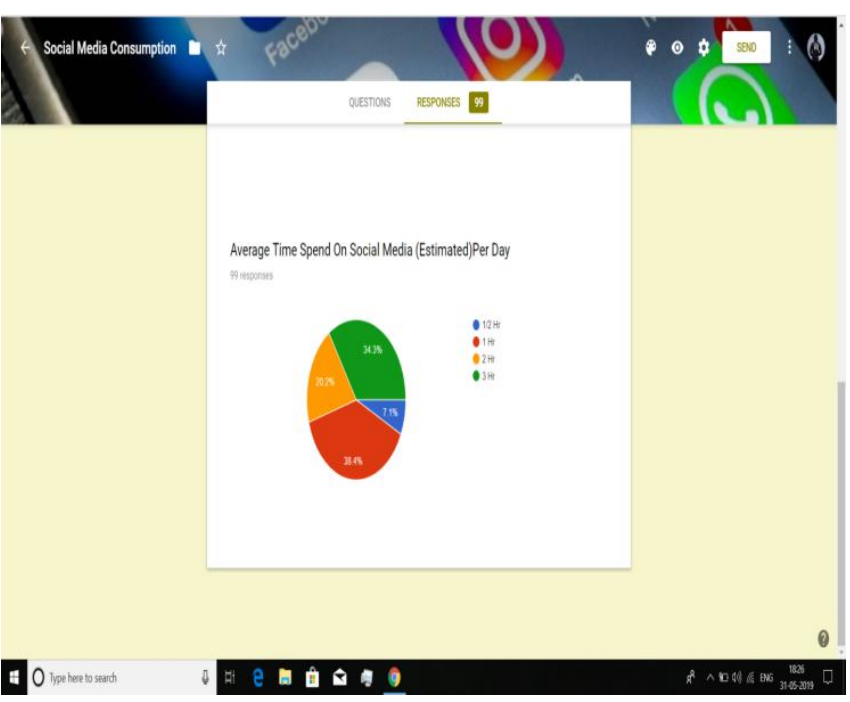

As the human is going through the rapid change in his social as well as in his economical aspect, it faces lot of changes in its social and ecological environment. As a result of it, social media playing a major role to connect the people from far places to communicate with each other on a platform where they can share their views. But as everything has its dark side it shows its consequences as many of people got addicted to the social media. When social media word in our mind then Facebook, WhatsApp, Instagram, LinkedIn are the most common example in it.

Now a days as looking to the scenario we are able to say that media has become a social need.

Hence, much like Maslow's hierarchy of needs in psychology, there are various levels in social media that are becoming galvanized within the discipline. Therefore, we've outlined each, starting from the bottom and working our way to the top. While this document is a generalization, we know that each client has specific needs and we can work with you to create customized solutions to meet them. [5]

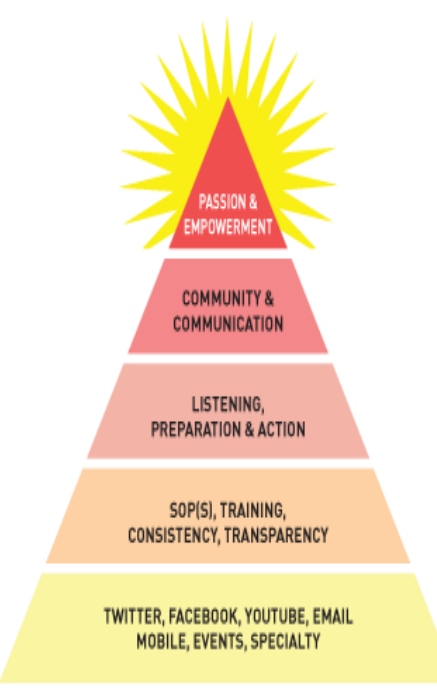

Published By: 


\section{HEALTH ISSUES}

We often hear from our parents or guardians that over using gadgets are harmful for health but do we have any proof for that?

We have to seek for the evidences when we made some allegation like this so for this to support that statement. We came with the studies which have been made by some of the trusted institution so in this context the studies were made by the University of Pittsburgh which relate the time spend using gadgets to mental health. According to studies Those who had spent more time on social media had 2.2 times the risk of reporting eating and body image concerns, compared to their peers who spent less time on social media. But it has some merits as well to some extents It's important to remember that teens are hardwired for socialization, and social media makes socializing easy and immediate. Teens who struggle with social skills, social anxiety, or who don't have easy access to face-to-face socializing with other teens might benefit from connecting with other teens through social media.

Too much time spent scrolling through social media can result in symptoms of anxiety and/or depression.

Here's how social media can be destructive:

\section{Focusing on likes:}

The need to gain "likes" on social media can cause teens to make choices they would otherwise not make, including altering their appearance, engaging in negative behaviors, and accepting risky social media challenges.

\section{Cyberbullying:}

Teens girls in particular are at risk of cyberbullying through use of social media, but teen boys are not immune. Cyberbullying is associated with depression, anxiety, and an elevated risk of suicidal thoughts.

\section{Making comparisons:}

Though many teens know that their peers share only their highlight reels on social media, it's very difficult to avoid making comparisons. Everything from physical appearance to life circumstances to perceived successes and failures are under a microscope on social media.

\section{Having too many fake friends:}

Even with privacy settings in place, teens can collect thousands of friends through friends of friends on social media. The more people on the friend list, the more people have access to screenshot photos, Snaps, and updates and use them for other purposes. There is no privacy on social media.

\section{CONCLUSION:}

In short we came to the conclusion that everything which we take in excess is not good for health in a same way social media was made to bring people close so that they can have conversation who live far away from each other but as the use of it increases it came with a side effect, which is highly addictive and it became part of the human life. Now living without mobile phone has become a very daredevil work or highly impossible for someone to do that. Nowadays some game has become so addictive to the students such that they can't imagine a single day without it. Many have been reported to the rehab so cure their addiction for game or mobile. Now a days nearly no is untouched with diseases of addiction for social media. We can't live for $10 \mathrm{~min}$ without checking WhatsApp whether some texted us or not. This is very bad habit of ours. The prevention for this is to limit the use it, and avoid unnecessarily chats and use of social media.

\section{REFERENCES}

1 Internet World Stats https://www.internetworldstats.com/stats.htm till 30June 2018.

2 Digital In 2018 https://wearesocial.com/us/blog/2018/01/global-digitalreport-2018 till Jan 2018.Sources: GlobalWebIndex GSMA Intelligence $\quad \underline{\text { Statista }}$ Locowise SimilarWeb (3) Ruder Finn, from US, Social media usage research

3 Akash deep Bhardwaj, Vinay Awasthi, Sam Gondar (Corresponding author: Akash deep Bhardwaj) University of Petroleum \& Energy Studies, Dehradun, India (Email: Bhrdwh@yahoo.com) Centrum Business School, Lima, Peru (Received June 2, 2017; revised and accepted Aug. 5, 2017)

4 We have conducted a survey on this issue and the data was collected in the Google Form and the provide the information of the survey.https://goo.gl/forms/QxcTLr5YBW1g90an2

5 https://www.starmark.com/blog/etips/understandinghierarchy-social-media/ 